\title{
Applications and Economics Aspects of Robotic Surgery
}

\author{
Fernando F. Nunes, Guilherme T. Kappaz, Maurice Y. Franciss, Leandro C. \\ Barchi*, Bruno Zilberstein \\ Gastromed Institute, Av. Nove de Julho, 4.440; Jd. Paulista- Cep: 01406-100, São Paulo, Brazil
}

Received: April 29, 2016; Accepted: July 05, 2016; Published: July 16, 2016

*Corresponding author: Leandro Cardoso Barchi, Gastromed Institute, Av. Nove de Julho, 4.440; Jd. Paulista-Cep: 01406-100, São Paulo, Brazil, Tel: +55-11-3082-8000; E-mail: leandrobarchi@hotmail.com

\section{Introduction}

Currently robotic surgery is widely accepted as a minimal invasive access and makes reference to surgery procedures assisted by electromechanical computer which serves as a bridge between the surgeon and his surgical actions on the patient. It requires a human operator to its activities, even when the operator is working remotely. The presence of robotic technology improves the activities of a human operator, but does not replace it.

The concept of robotic surgery begins with the work of Scott Fisher (NASA) in the second half of the 80s, while developing virtual reality projects associated with 3 -dimensional images. At the end of that decade, the start and development of laparoscopic surgery was presented as a revolution in the operating concept of that time, which was characterized by the statement "great surgeons, large incisions" with Jacques Perissat's pioneer laparoscopic cholecystectomy. Just after that period Richard Satava and NASA began to develop studies on telesurgery into a military program. In the early $90 \mathrm{~s}$, several surgical robotic systems began to take place, such as RoboDoc ${ }^{\circledR}$, capable of performing vascular anastomosis and Artemis ${ }^{\circledR}$ with remote handling. In 1992, the US military developed the DARPA ${ }^{\circledR}$ program, in order to save soldiers on the battlefield using high technology, where a vehicle equipped with high-tech imaging could make diagnosis and initiate procedures remotely to where the wounded soldier was located. In 1993, Alberto Roveda performed liver biopsy in swine, with the surgical station located in the Laboratory of NASA in Pasadena, California, and the animal far distant in Milan. From this and other experiences, robot surgery commercial activities took place and the first one to be used was AESOP ${ }^{\circledR}$, a mechanical arm which used voice command to control the optical movement on videosurgery. Soon, Zeus ${ }^{\circledR}$ and Da Vinci ${ }^{\circledR}$ surgical systems were developed, and in 1997 the first robotic surgery was performed in the city of Brussels, by Jacques Himpens and Cardiere. From that date on, various procedures with different complexities had been performed with this technology.

\section{Applications}

Robotic surgery is seen as a promise in several surgical areas, as there is no strong scientific evidence demonstrating increased rates of surgical complications compared to conventional or even laparoscopic surgery. In general, there is a common opinion about the needs of years of training and experience to perform procedures using remote technology. The literature suggests advantages over other forms of surgical access, including superior visualization of the operative field with images in three dimensions compared to traditional laparoscopy and better surgical ergonomics; and present as disadvantages the size of materials, the lack of flexibility of power devices and the difficulty to perform operations that use different quadrants or surgical sites. This technology is not yet widely available to all surgeons and training is still not accessible.

\section{Pelvic Surgery}

Perhaps the greatest enthusiasm in robotic surgery points to pelvic surgery because of its good mobility and performance in a restricted confined field when compared to conventional or laparoscopic surgery. In 2009, a report about the acceptance of robotic surgery showed that 795 units of Da Vinci ${ }^{\circledR}$ were sold in December 2007, mostly in North America and Europe, and in the same period 50,000 radical prostatectomies were performed in the US, with $60 \%$ of penetrance of these surgeries in the US market, with an increase of $50 \%$ over the previous year. Despite its advantages, high costs and longer operative time were disadvantages found about this technology $[1,2]$. Randomized and non-randomized studies have confirmed the benefits of laparoscopy in rectal cancer surgery. However, due to long learning curve and high conversion rate, the global impact of the use of this method is still modest, especially in obese male patients. It is estimated that only $10 \%$ of colorectal cancer surgeries are currently treated by laparoscopy, with increasingly use of robotic platforms added to the perspective of visualization improvement, exposure and dissection of important structures in narrow space, such as the pelvic cavity. Besides all that, the great mobility of instruments, capable to rotate from $180^{\circ}$ to $540^{\circ}$ allows better performance in the pelvic cavity [3]. There are even better results in the quality of oncological resection with clearer margins, higher number of lymph nodes resection and decrement of surgical complications as the learning curve is exceeded 
[3]. Precise dissections provide fewer complications related to erectile dysfunction in postoperative of total mesorectum resection in rectal cancer surgery after 3 months of surgery. This time was also sufficient to significant reduce urinary dysfunction. In patients receiving different approaches, same results are reached after 6 months postoperatively [4]. Other studies demonstrate that the conversion rate to open surgery is almost $5 \%$ smaller in robotic or robot-assisted surgeries groups when compared to traditional laparoscopy. However, most reports do not show statistical difference between minimally invasive methods regarding conversion rate. Yet, there is little bleeding (mean of $283 \mathrm{ml}$ in the European study) considering an average of surgical time of 297 minutes, well accepted for this surgery risk level. Surgical margins were considered appropriate in several studies, with 97\% survival in 3 years [4-6].

\section{Gynecology}

Robotic surgery is considered purely an extension of laparoscopic surgery, with improvements in the surgeon's ergonomics and more precise movements due to trembling corrections, 3-D vision, and movement accuracy, among other reasons. It is considered by some American authors as the best minimally invasive method for the treatment of malignant gynecologic lesions, presenting reduction of operative time, ranging from 4.5 to 10 hours, and lesser bleeding, with volumes from 50 to 1500 milliliters. It is also considered the best option for complex surgeries such as myomectomy, hysterectomy and deep endometriosis [5-6]. It was also identified shorter hospitalization stays, less postoperative pain and better lymph node dissections in oncologic surgery compared to open and laparoscopic surgery $[6,7]$.

\section{General Surgery}

In general surgery, the use of robotics contributes to improvement of dissection in oncological surgeries and better image quality by three-dimension platform as in any other procedure. However, it has the limitation to be mostly used in single abdominal quadrant surgeries. It presents the advantage of better dissection in complex surgeries, safer micro suture as well as reconstructions. In surgery for morbid obesity it is possible to conclude that there are better outcomes when using robotic technology, mainly in revisional surgeries. The operative time ranges from 90 to 300 minutes, with very low conversion and complication rates, as well as mortality. These results are similar to those found in laparoscopy surgery, independently of the surgical technique (Sleeve Gastrectomy or Gastric Bypass), but with much higher costs $[6,8]$. In surgery for achalasia, it has been proven that after 30 procedures performed robotically, surgical time of myotomy with partial flap is equivalent to the same surgery performed by laparoscopy. Bleeding and hospital stay did not change in relation to the technique used. Nevertheless, there were more complications in laparoscopic surgeries compared to robotic surgery, with $8 \%$ more esophageal perforations for the first procedure, all corrected immediately and without clinical consequences for the patient $[9,10]$.

\section{Cardiothoracic Surgery}

Cardiothoracic procedures require concentration and precision from the surgeons. In Lung resection, studies have shown that difficulties were overcome with the use of robotic in thoracic surgery, mainly due to ergonomics because of the presence of only the robot arms and the assistant in the surgical field, avoiding the inconvenience of collisions between two people in tight space. Three-dimension high quality visions are a significant differential, which adds to the procedure, more accurate resections and free margins. The same benefits are found in cardiac surgery such as valve replacements, where the improvement of image quality and accuracy of movements, minor camera movements compared to those made by human hand, such as tremors and rotation, significantly reduces surgical time. Thus, it keeps surgeons with better proportion of time and maximum concentration on the procedure. According to Park, et al, the disadvantages of this technology are the difficulty of surgeon training and the costs of the materials. In their report, the cost for annual maintenance is US $\$ 100,000$. The robotic instruments have a finite number of uses that varies from 10 to 12 , depending on the instrument. Each instrument costs $\$ 2000$ and can be used for 10 times, with a cost of US\$200 per case. The drapes used for the robot arms and camera cost US $\$ 130$, so that the total disposable cost per case is US\$730. Associate with the huge initial investment to acquire the robot platform, this will be the most difficulty for emergent countries to apply the robot technique routinely $[11,12]$.

\section{Pediatric Surgery}

Minimally invasive surgery with robotic assistance is considered very safe in pediatric patients and can be applied in various areas of pediatric surgery. Cholecystectomy is excellent for the development and training of new surgeons joining this technology. Procedures considered delicate and complex, such as hepatobiliary, urological pyeloplasty and solid tumors in thoracic surgery are ideal for this technology due to augmentation in technical accuracy. Procedures like esophagostomy and enterostomy gather the group of operations indicated for robotic surgery, without increasing complications neither surgical. Nonetheless, randomized trials must be performed in order to confirm the advantages of robotic surgery in the pediatric population $[13,14]$.

\begin{tabular}{|l|l|}
\hline Table 1: Advantages and disadvantages of robotic surgery. \\
\hline Advantages & Disadvantages \\
\hline Best view quality & Initial investiments \\
\hline 3D view & Coasts of the materials \\
\hline Less & Coast of manutention \\
\hline shorter hospital length of stay & Difficulty of surgeon training \\
\hline lesser bleeding & $\begin{array}{l}\text { Instruments have a finite } \\
\text { number of uses }\end{array}$ \\
\hline Camera rotate from $180^{\circ}$ to $540^{\circ}$ & \\
\hline Better precision of dissection & in \\
\hline $\begin{array}{l}\text { More linphonodes dissection } \\
\text { oncologicals surgeries }\end{array}$ & \\
\hline Less functionals urologic complications & \\
\hline Surgeon confort & \\
\hline
\end{tabular}




\section{Costs}

The main disadvantage found when comparing roboticsurgery to conventional laparoscopy is the high cost of the technology. According to Barbash and Glied, the acquisition of a unit may cost from US\$ 1 to US\$ 2.5 million to a hospital. Estimation on robotic surgery costs varies according to assumptions about the frequency which the robot is used. Reports about the analysis of robot-assisted procedures costs published since 2005 in a range of 20 different surgical procedures, the additional variable cost of using this technology was US\$ 1.600 more expensive. When the amortized cost of the robot itself was included, the total additional cost of using a robot-assisted procedure rose to US $\$ 3.200$. Because there is only one company responsible for manufacturing the platforms used in robotic surgery, the prices exercised by the market are still very high. It is believed that in the near future, with the emergence of new technology and the breaking of the current monopoly, the cost will be reduced, thereby reducing the amount paid out per procedure $[10,15]$ Robotic systems also require high cost maintenance fee and specific materials expenses. The use of robotic systems may also require longer operating time than alternative techniques. Some of the new costs will be offset by reducing postoperative in-hospital costs, reducing hospital stays with better and quicker patient recovery and also quicker return to work $[10,15]$.

\section{Conclusion}

The use of robotic surgery has increased in all major centers. Technical advantages such as better precision movements and three-dimension images turn the procedures safer and may decrease surgical time. These advantages are gained according to the improvement in the experience of the surgeon. The high cost is still considered the main hindrance in the use of this technology, but the expectation is that, with new companies' development, costs will decrease. These higher costs may be attenuated by faster recovery, shorter hospitality stay and faster return of the patient to its activities, which leads us to consider that this technology as viable and promising.

\section{References}

1. Skinovsky, James, Chibata, Maurício, Siqueira, Daniel Emilio Dalledone. Virtual Reality and Robotics In Surgery: Where We Are And Where We Are Heading. 2008;35(5):334-337.

2. Wexner SD, Bergamaschi R, Lacy A, Udo J, Brölmann H, Kennedy $\mathrm{RH}$, et al. The current status of robotic pelvic surgery: results of a multinational interdisciplinary consensus conference. Surg Endosc. 2009;23(2):438-43. doi: 10.1007/s00464-008-0202-8.
3. Ramos JR, Parra-Davila E. Four-arm single docking full robotic surgery for low rectal cancer: technique Standardization, Rev Col Bras Cir. 2014;41(3):216-23.

4. Kim JY, Kim NK, Lee KY, Hur H, Min BS, Kim JH. A Comparative Study of Voiding and Sexual Function after Total Mesorectal Excision with Autonomic Nerve Preservation for Rectal Cancer: Laparoscopic Versus Robotic Surgery. Ann Surg Oncol. 2012;19(8):2485-93. doi: 10.1245/s10434-012-2262-1.

5. Diaz-Arrastia C, Jurnalov C, Gomez G, Townsend C Jr. Laparoscopic hysterectomy using a computer-enhanced surgical robot. Surg Endosc. 2002;16(9):1271-3. Epub 2002 Jun 27.

6. Magrina JF. Robotic surgery in gynecology. Eur J Gynaecol Oncol. 2007;28(2):77-82.

7. Cho JE, Shamshirsaz AH, Nezhat C, Nezhat C, Nezhat F. New technologies for reproductive medicine: laparoscopy, endoscopy, robotic surgery and gynecology. A review of the literature. Minerva Ginecol. 2010;62(2):137-67.

8. Romero RJ, Kosanovic R, Rabaza JR, Seetharamaiah R, Donkor C, Gallas M, Gonzalez AM. Robotic SleeveGastrectomy: Experience of 134 Cases andComparisonwith a SystematicReviewoftheLaparoscopic Approach. Obes Surg. 2013;23(11):1743-52. doi: 10.1007/s11695013-1004-1.

9. Diamantis T, Alexandrou A, Nikiteas N, Giannopoulos A, Papalambros E. Initial Experience withRoboticSleeveGastrectomy for MorbidObesity. Obes Surg. 2011;21(8):1172-9. doi: 10.1007/s11695-010-0242-8.

10. Horgan S, Galvani C, Gorodner MV, Omelanczuck P, Elli F, Moser F, et al. Robotic-assisted heller myotomy versus laparoscopic heller myotomy for the treatment of esophageal achalasia: multicenter study. J Gastrointest Surg. 2005;19(81):1020-1030.

11. Schmid T, Augustin F, Kainz G, Pratschke J, Bodner J. Hybrid VideoAssisted Thoracic Surgery-Robotic Minimally Invasive Right Upper Lobe Sleeve Lobectomy . Ann Thorac Surg. 2011;91(6):1961-5. doi: 10.1016/j.athoracsur.

12. Alqahtani A, Albassam A, Zamakhshary M, Shoukri M, Altokhais T, Aljazairi A, Alzahim A, Mallik M, Alshehri A. Robot-Assisted Pediatric Surgery: How Far Can We Go?. World J Surg. 2010;34(5):975-8. doi: 10.1007/s00268-010-0431-6.

13. Lee RS, Retik AB, Borer JG, Peters CA. Pediatric Robot Assisted Laparoscopic Dismembered Pyeloplasty:Comparison With a Cohort of Open Surgery. J Urol. 2006;175(2):683-7; discussion 687.

14. Meehan JJ, Sandler A. Pediatric robotic surgery: A single-institutional review of the first 100 consecutive cases. Surg Endosc. 2008;22(1):17782.

15. Huffmanm LC, Pandalai PK, Boulton BJ, James L, Starnes SL, Reed MF, Howington JA, Nussbaum MS. Robotic Heller myotomy: A safe operationwithhigherpostoperativequality-of-life indices. Surgery. 2007;142(4):613-8; discussion 618-20. 